\title{
Evaluation of fiber diameter and morphology differences for electrospun fibers on bacterial immobilization and bioremediation performance
}

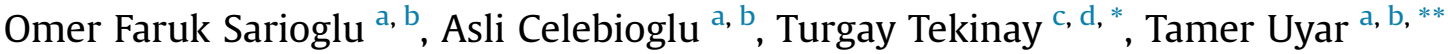 \\ a Institute of Materials Science \& Nanotechnology, Bilkent University, 06800, Bilkent, Ankara, Turkey \\ ${ }^{\mathrm{b}}$ UNAM-National Nanotechnology Research Center, Bilkent University, 06800, Bilkent, Ankara, Turkey \\ ${ }^{\mathrm{c}}$ Life Sciences Application and Research Center, Gazi University, 06830, Golbasi, Ankara, Turkey \\ d Department of Medical Biology and Genetics, Faculty of Medicine, Gazi University, 06500, Besevler, Ankara, Turkey
}

\section{A R T I C L E I N F O}

\section{Article history:}

Received 25 November 2016

Received in revised form

7 February 2017

Accepted 7 February 2017

Available online 16 February 2017

\section{Keywords:}

Ammonium

Bacterial immobilization

Bioremediation

Electrospinning

Methylene blue

Polysulfone

\begin{abstract}
A B S T R A C T
In this report, morphology and fiber diameter differences of electrospun polysulfone (PSU) fibers on bacterial immobilization and bioremediation performance were evaluated. PSU fibers were produced with aligned or randomly oriented morphologies, and PSU fibers with thinner and thicker diameters were also produced. PSU fibers were utilized as carrier matrices for bacterial integration and the sample showing highest bacterial immobilization was tested for bioremediation of ammonium and methylene blue dye in water. It was found that randomly oriented and thinner PSU fibers are the optimal system for bacterial immobilization, hence bioremediation studies were performed with this sample. The results demonstrated that bacteria immobilized PSU fibers are promising candidates for simultaneous removal of ammonium and methylene blue dye, and they have a potential to be used in remediation of water systems.
\end{abstract}

๑) 2017 Elsevier Ltd. All rights reserved.

\section{Introduction}

Industrial wastewater contains different types of contaminants, and nitrogenous wastes and dyes are two common types of water contaminants. Ammonia $\left(\mathrm{NH}_{3}\right)$, or the ionized form ammonium $\left(\mathrm{NH}_{4}^{+}\right)$, is one of the most common nitrogenous water contaminant that is found naturally in aquatic ecosystems or produced as a result of industrial processes, and is highly toxic for many organisms above certain thresholds. United States Environmental Protection Agency (US EPA) regulates the acceptable limits for ammonia and its two main metabolic byproducts, nitrite and nitrate, so that ammonia concentration should not exceed $1.5 \mathrm{mg} / \mathrm{L}$, nitrite concentration should not exceed $1 \mathrm{mg} / \mathrm{L}$, nitrate concentration should

\footnotetext{
Abbreviations: MB, Methylene blue; PSU, Polysulfone.

* Corresponding author. Life Sciences Application and Research Center, Gazi University, 06830, Golbasi, Ankara, Turkey.

** Corresponding author. Institute of Materials Science \& Nanotechnology, Bilkent University, 06800, Bilkent, Ankara, Turkey.

E-mail addresses: ttekinay@gmail.com (T. Tekinay), uyar@unam.bilkent.edu.tr (T. Uyar).
}

not exceed $10 \mathrm{mg} / \mathrm{L}$, and the sum of nitrite and nitrate concentration should not exceed $10 \mathrm{mg} / \mathrm{L}$ in drinking water (NJDEP, 1997; US EPA, 2009). Therefore, remediation of ammonia and its derivatives from aquatic systems is essential for sustainable water use. Bioremediation is a very common procedure for removal of nitrogenous wastes in water due to its sustainability and biofriendliness, and specific microorganisms have been used for this purpose. Among different types of systems, heterotrophic ammonium removal by a single nitrifier/denitrifier system is advantageous since simultaneous processing of nitrification and denitrification can be possible in this system and due to contamination of different organic wastes as potential carbon sources, industrial wastewater is more favorable for heterotrophic removal. In addition to nitrogenous wastes, dyes also comprise a great portion of industrial contaminants. Dyes have diverse application areas and are widely used for many industrial processes. Nevertheless, their decontamination is an important issue and novel strategies are in search for greener treatment. Bioremediation is an alternative green approach for removal of dyes in water systems, and it enables efficient, environmentally friendly, cost-effective and sustainable remediation (Malik, 2004). 
In addition to free-bacteria cells, bacteria immobilized biohybrid systems have also been utilized for water treatment. These bio-hybrid materials can bring certain advantages over freebacteria such as lower space and growth medium requirements, easier handling and potential reusability of the system. As carrier matrices, electrospun fibrous webs are promising candidates for immobilization of bacterial cells since electrospinning is a simple, low-cost and versatile fabrication method and it enables tunable production of fibrous networks (e.g. higher porosity) (Ramakrishna et al., 2005; Salalha et al., 2006; Greiner and Wendorff, 2007; Wendorff et al., 2012). There are number of studies in the literature regarding the use of microorganism-integrated electrospun fibrous biocomposites for bioremediation of water systems (Klein et al., 2009, 2012; Eroglu et al., 2012; Sarioglu et al., 2013; San et al., 2014; San-Keskin et al., 2015a,b; Sarioglu et al., 2015, 2016). However, the effect of different fiber morphologies and the effect of fiber diameter for bacterial immobilization on these electrospun fibers have not been studied in detail.

In the present study, different types of electrospun polysulfone (PSU) fibers (with different morphologies and different fiber diameters) were produced to determine the most favorable system for bacterial integration. PSU was chosen in this study for water filtration applications since it is a widely used polymeric material in this area. Previously, it was shown that electrospun PSU fibers can be used as a carrier fibrous matrix for bacterial immobilization for the purpose of bioremediation of water systems (Sarioglu et al., 2016). For the bacterial strain, Acinetobacter calcoaceticus STB1 strain was chosen since it was previously presented as promising for ammonium remediation in water and it could remove even high concentrations of this contaminant at heterotrophic conditions (Sarioglu et al., 2012). The dye removal capability of this strain was unknown, hence it was aimed to evaluate the dye removal characteristics of this strain for potential bioremediation applications in the present study. Electrospun PSU fibrous webs with optimal morphology and fiber diameter for bacterial immobilization was chosen and then tested for simultaneous removal of ammonium and methylene blue dye at differential concentrations. This type of system is promising for potential wastewater treatment applications after successful optimizations.

\section{Materials and methods}

\subsection{Electrospinning of PSU fibers}

Aligned and randomly oriented PSU fibers were produced by different systems. The homogenous electrospinning solutions were prepared by dissolving 32\% (w/v) polysulfone (PSU, Mw 60,000, Scientific Polymer Products, Inc.) in N,N-dimethylacetamide/ acetone (9/1, (v/v)) (DMAC, Sigma-Aldrich, 99\%; acetone, SigmaAldrich, $\geq 99 \%(\mathrm{GC})$ ) binary solvent mixture, and $2 \%$ of $\mathrm{NaCl}$ (Sigma-Aldrich, $\geq 99 \%$ ) was added to some samples to increase conductivity of the solution and decrease the fiber diameter. Polymer solutions were loaded in a syringe with inner diameters of $0.4-0.6 \mathrm{~mm}$. The syringe was located horizontally and connected with a syringe pump (model KDS-101, KD Scientific, USA), and the electrode of the high-voltage power supply (Spellman, SL30, USA) was clamped to the metal needle tip, while the aluminum collectors were grounded. Electrospinning parameters were adjusted as follows: feed rate of solutions $=0.5 \mathrm{~mL} / \mathrm{h}$, applied voltage $=10-15 \mathrm{kV}$, tip-to-collector distance $=10-12 \mathrm{~cm}$. For the production of randomly oriented PSU fibers, electrospun fibers were deposited on a grounded stationary plate metal collector covered with aluminum foil. For the production of aligned PSU fibers, electrospun fibers were deposited on a grounded cylindrical collector covered with aluminum foil, which was rapidly rotating by the aid of a rotary motor ( $3000 \mathrm{rpm}$ ) to align electrospun fibers in a parallel orientation. The electrospinning apparatus was inside a Plexiglas box, and the process was performed at room temperature and $20 \%$ relative humidity. Collected PSU fibers were then dried in a fume hood for overnight to remove residual solvent.

\subsection{Procurement of the Acinetobacter calcoaceticus STB1 strain and initial characterization}

The bacterial strain (Acinetobacter calcoaceticus STB1) utilized in this study was previously isolated from a hatchery. This strain is known to be capable of ammonium removal and was also tested for methylene blue dye removal in this study. All bacterial cultures were grown in a specific growth medium, which does not contain nitrogenous sources besides external addition of ammonium. The ingredients of the bacterial growth medium were: $6.3 \mathrm{~g} / \mathrm{L} \mathrm{Na}_{2} \mathrm{HPO}_{4}$ ( $\geq 99 \%$ ), $3 \mathrm{~g} / \mathrm{L} \mathrm{KH} \mathrm{PO}_{4}$ ( $\geq 99 \%$ ), $0.5 \mathrm{~g} / \mathrm{L} \mathrm{NaCl}$ ( $\left.\geq 99.5 \%\right), 2 \mathrm{~g} / \mathrm{L}$ glucose (anhydrous), and $300 \mathrm{~mL} / \mathrm{L}$ of a trace elements solution consisting of $6.1 \mathrm{~g} / \mathrm{L} \mathrm{MgSO} 4$ ( $\geq 99.5 \%$ ), $3 \mathrm{~g} / \mathrm{L} \mathrm{H}_{3} \mathrm{BO}_{3}$ ( $\geq 99.5 \%$ ), $0.5 \mathrm{~g} / \mathrm{L} \mathrm{MnCl}_{2}$ ( $\geq 99 \%$ ), $0.05 \mathrm{~g} / \mathrm{L} \mathrm{CaCl}_{2}$ ( $\geq 93 \%$ ), $0.03 \mathrm{~g} / \mathrm{L} \mathrm{FeSO}_{4} \cdot 7 \mathrm{H}_{2} \mathrm{O}$ ( $\geq 99 \%$ ), $0.03 \mathrm{~g} /$ $\mathrm{L} \mathrm{CuCl}_{2}$ ( $\geq 97 \%$ ), $0.03 \mathrm{~g} / \mathrm{L} \mathrm{ZnCl}_{2}$ ( $\geq 99.99 \%$ ). Ammonium removal capability of STB1 strain was tested by external addition of ammonium chloride (in the form of $\mathrm{NH}_{4} \mathrm{Cl}, \geq 99.5 \%$ ) to the bacterial growth media, to provide the initial ammonium concentrations of 25,50 and $100 \mathrm{mg} / \mathrm{L}$. Methylene blue (MB, $\geq 82 \%$ ) dye removal capability of STB1 strain was also tested separately, with having a constant concentration of ammonium ( $50 \mathrm{mg} / \mathrm{L}$ ) and varying concentrations of $\mathrm{MB}(25,50,100 \mathrm{mg} / \mathrm{L})$ in the growth media. All reagents utilized were purchased from Sigma-Aldrich (USA).

\subsection{Immobilization of bacteria on PSU fibers}

Bacterial immobilization was achieved by the inclusion of equivalent PSU fibers ( $2.8 \mathrm{mg}$ per $\mathrm{mL}$ ) in newly inoculated STB1 cells containing LB growth medium (Luria-Bertani: $10 \mathrm{~g} / \mathrm{L}$ tryptone, $5 \mathrm{~g} / \mathrm{L}$ yeast extract, $10 \mathrm{~g} / \mathrm{L} \mathrm{NaCl}$ in $1 \mathrm{~L}$ of distilled water, $\mathrm{pH}$ 7.0). Bacterial colonies were maintained for 21 days at $150 \mathrm{rpm}$ and $30{ }^{\circ} \mathrm{C}$ for immobilization onto the fiber surfaces. After 7 and 21 days of incubation, bacterial immobilization was checked by scanning electron microscopy (SEM) imaging, and the quantitative analysis of bacterial adhesion was evaluated by a specific procedure, in which immobilized bacteria were detached from the fiber surfaces via sequential vortexing and sonication, and the detached bacteria were utilized for cell viability assessments (Sarioglu et al., 2015). After this evaluation, the sample showing the highest bacterial cell viability at equivalent conditions was selected for use in application studies.

\subsection{Methylene blue and ammonium bioremoval experiments}

Bacterial cultures were grown in the same basal growth medium with external additions of both methylene blue (MB) and ammonium into the solution. Equivalent pieces of bacteria immobilized PSU fibers (with $\mathrm{w} / \mathrm{v}$ ratio of $0.5 \mathrm{mg} / \mathrm{mL}$ ) were added directly to the bacteria containing growth media, and the samples were incubated for $72 \mathrm{~h}$ at $150 \mathrm{rpm}$ and $30^{\circ} \mathrm{C}$. Pristine PSU fibers were also tested for simultaneous removal of $\mathrm{MB}$ and ammonium to determine the role of bacterial presence for the removal of these contaminants. The initial MB concentration was fixed at $25 \mathrm{mg} / \mathrm{L}$ for bacteria immobilized PSU fibers, while the initial ammonium concentrations were varying $(25,50,100 \mathrm{mg} / \mathrm{L})$. The initial MB concentration was also same for pristine PSU fibers ( $25 \mathrm{mg} / \mathrm{L})$, while the initial ammonium concentration was $100 \mathrm{mg} / \mathrm{L}$. Liquid samples were collected periodically to measure the remaining concentrations of ammonium and MB. Changes in ammonium concentrations were determined by a spectrophotometric test kit (Merck Ammonium 
Cell Test 14559) and changes in MB concentrations were determined by a spectrophotometer as well, by measuring the specific absorbance of the dye at $660 \mathrm{~nm}$. Before performing the tests, samples were centrifuged for $5 \mathrm{~min}$ at $8000 \mathrm{rpm}$ at room temperature, and the supernatants were used to measure the remaining concentrations of ammonium or MB to prevent the interference coming from bacterial cells. Merck Ammonium Cell Test (14559) was used as ammonium detection method which measures both ammonium ions and dissolved ammonia in variety of aquatic environments. The method is analogous to some accredited ammonium detection methods such as EPA 350.1, APHA 4500-NH3 D, ISO $7150 / 1$ and DIN $38406 \mathrm{E} 5$, so it is quite reliable for detection of ammonium. This method was previously applied for detection of the remaining ammonium in water (Sarioglu et al., 2012, 2013). MB detection method is also quite reliable and it was applied for detection of MB in water formerly (San et al., 2014; Sarioglu et al., 2017). All tests were done in triplicate.

\subsection{Scanning Electron Microscopy (SEM)}

Small PSU fiber samples with and without bacterial immobilization were prepared for SEM analyses. The samples were fixed by incubation in a $2.5 \%$ glutaraldehyde solution, and then dehydrated by immersion in a series of ethanol water solutions (30\%-96\%). All samples were coated with 5-10 nm layer of gold-palladium prior to the analysis, and a Quanta 200 FEG scanning electron microscope (FEI Instruments, USA) was used for imaging.

\subsection{Statistical analysis}

One-way ANOVA test was applied for statistical analysis. Analysis was done by using GraphPad Prism 5 (GraphPad, USA) at a 0.05 level of probability.

\section{Results and discussion}

\subsection{Fiber morphology and diameter differences on bacterial immobilization}

Polysulfone (PSU) has already been used for water filtering applications and bio-integrated application studies (Sarioglu et al., 2016). Electrospun PSU fibers were used as substrates for bacterial immobilization and the hybrid system was utilized for water cleaning purposes. As seen in Fig. 1, PSU fibers were obtained with aligned and randomly oriented morphologies with different fiber diameters. It is known that the addition of salt to the polymer solution decreases the fiber diameters of the electrospun fibers due to the increase of solution conductivity which results in more stretching of the jet during electrospinning process (Uyar and Besenbacher, 2008). The fiber diameters of electrospun PSU fibers were measured as $1520 \pm 55 \mathrm{~nm}$ for parallel oriented sample and $1455 \pm 85 \mathrm{~nm}$ for randomly oriented sample. With the addition of salt, electrospun PSU fibers were obtained with the diameters of $865 \pm 85 \mathrm{~nm}$ for parallel oriented sample and $1065 \pm 140 \mathrm{~nm}$ for randomly oriented sample. In order to preserve the parallel orientation for aligned PSU fibers, both aligned and randomly oriented PSU fibers were not detached from the aluminum foil and equivalent pieces (with $\mathrm{w} / \mathrm{v}$ ratio of $2.8 \mathrm{mg} / \mathrm{mL}$ ) were cut and prepared from those samples. These samples were added to bacterial cultures and immobilization of bacteria onto fiber surfaces was aimed during incubation. At days 7 and 21, equivalent samples were taken and SEM analysis was applied on these samples. In addition, bacterial immobilization was quantitatively evaluated by a protocol after finishing the incubation, which allows quantification of previously immobilized bacteria by viable cell counting assay (VCC). According to SEM imaging (Fig. 2), there are some disruptions in the parallel orientation for aligned PSU fibers on days 7 and 21, which might be caused by shaking and fixation, though still these fibers have more aligned morphology and the morphology difference at the initial contact was supposed to be meaningful for characteristic immobilization.

Seven days of bacterial immobilization was found as inadequate and therefore bacterial incubation was maintained for 21 days. Bacterial immobilization was found as sufficient after 21 days of incubation, and therefore equivalent samples were utilized for cell viability assessments. As seen in Fig. 3, the cell viabilities were found as higher for thinner PSU fibers, plus randomly oriented and thinner PSU fiber sample was the best sample showing the highest bacterial cell viability for the immobilized cells. The means of different samples were not found as significantly different from each other $(p=0.7295)$. It was deduced that this result was due to the size of bacteria $(1.0-1.5 \mu \mathrm{m})$ and the presence of more available spaces for attachment in randomly oriented fibers. At the end of this experiment, randomly oriented and thinner PSU fiber sample was selected as the carrier matrix for bacterial integration, and further studies were performed on this sample.

\subsection{Simultaneous removal of $M B$ and ammonium by bacteria immobilized PSU fibers}

STB1 strain was initially tested for MB and ammonium removal for use in further studies. MB removal by STB1 strain was tested at a constant ammonium concentration ( $50 \mathrm{mg} / \mathrm{L}$ ), which was the only nitrogen source in the medium for bacteria. As seen in Fig. 4a, the removal efficiency decreases with an increase in the MB concentration, and the highest removal yield was observed at $25 \mathrm{mg} / \mathrm{L}$ of initial MB ( 40\%). Nevertheless, complete removal of ammonium was observed for each sample at the tested concentrations. Based on this result, it was aimed to test the simultaneous removal of $\mathrm{MB}$ and ammonium by bacteria immobilized PSU fibers while keeping the initial MB concentration constant at $25 \mathrm{mg} / \mathrm{L}$.

Fig. $4 \mathrm{~b}$ shows that, bacteria immobilized PSU fibers have shown efficient removal of ammonium at three different initial concentrations $(25,50$ and $100 \mathrm{mg} / \mathrm{L})$ within $72 \mathrm{~h}$ and complete removal
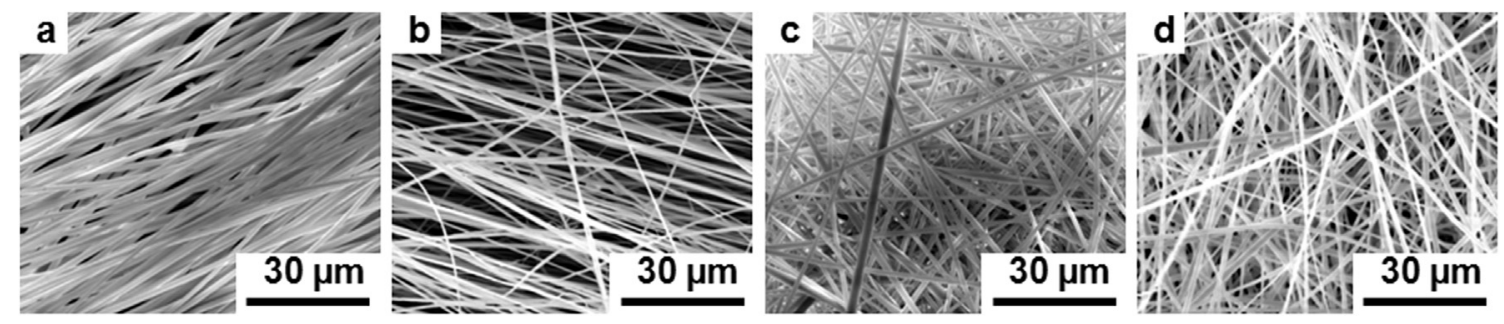

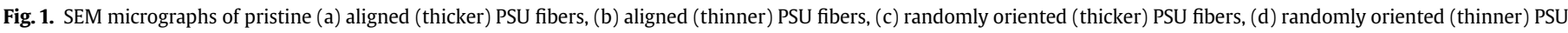
fibers. 

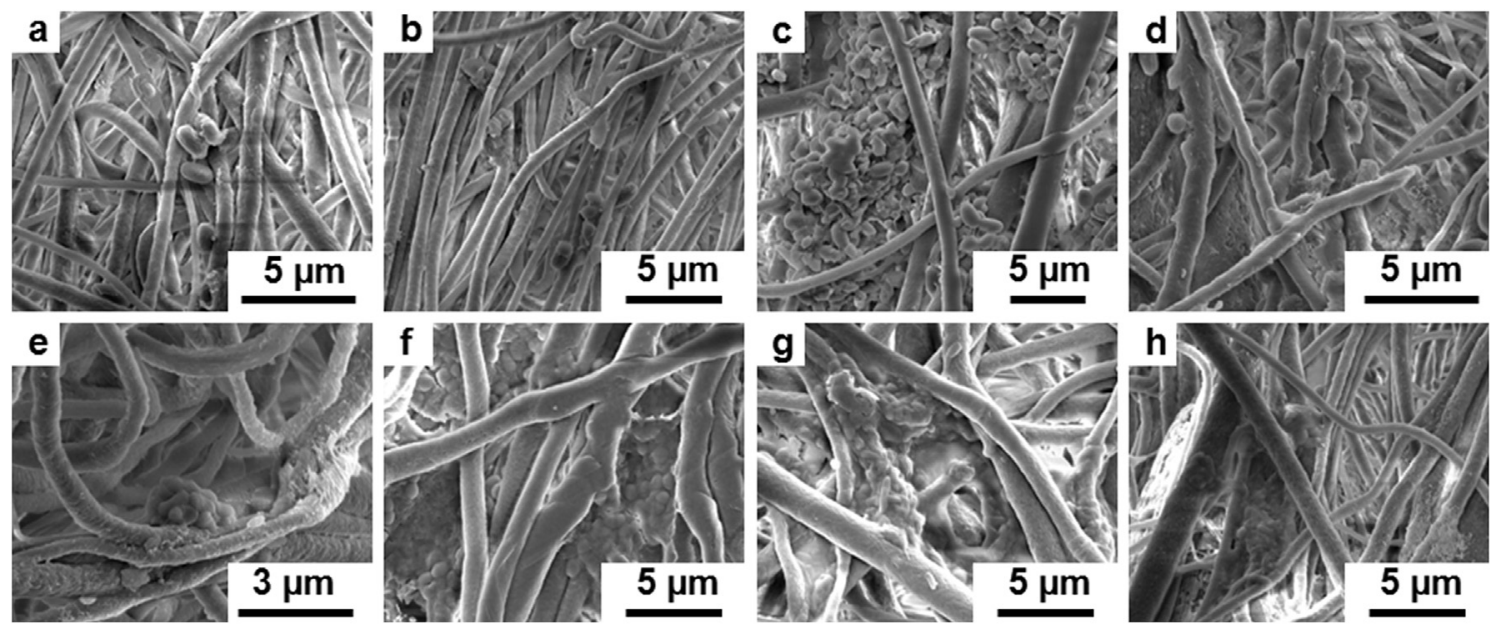

Fig. 2. SEM micrographs of bacteria immobilized (a, e) aligned (thicker) PSU fibers, (b, f) aligned (thinner) PSU fibers, (c, g) randomly oriented (thicker) PSU fibers, (d, h) randomly oriented (thinner) PSU fibers. (a-d) correspond to bacteria immobilized PSU fibers after 7 days of incubation, (e-f) correspond to bacteria immobilized PSU fibers after 21 days of incubation.

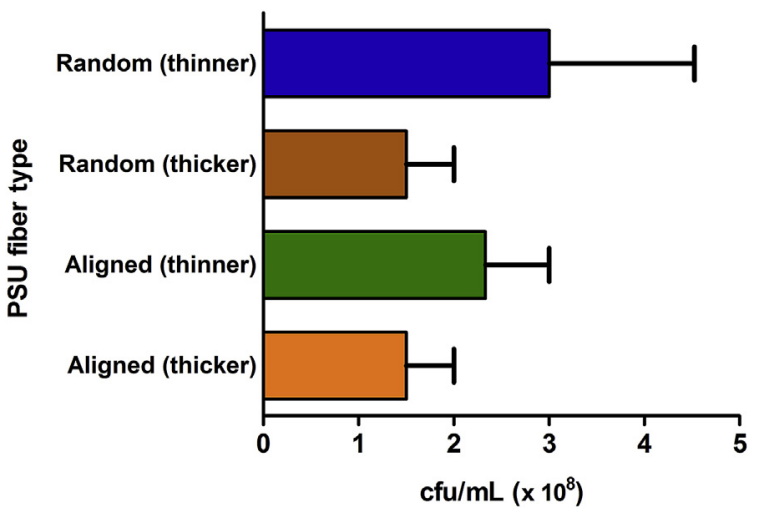

Fig. 3. VCC (Viable cell counting) assay results of random (thinner), random (thicker), aligned (thinner), aligned (thicker) PSU fibers after 21 days of incubation period. the sample having $100 \mathrm{mg} / \mathrm{L}$ of initial ammonium (55\%). It was found that, $\mathrm{MB}$ removal yield increased with an increase in the initial ammonium concentration at the tested concentrations, which suggests simultaneous removal of $\mathrm{MB}$ and ammonium might be achieved with desirable removal efficiencies after successful optimizations.

As a control study, the removal capability of pristine PSU fiber sample was tested for MB and ammonium at initial concentrations of $25 \mathrm{mg} / \mathrm{L}$ and $100 \mathrm{mg} / \mathrm{L}$, respectively (data not shown). The removal performances of pristine PSU fiber sample were low, such that the MB removal capability was around $0.5 \%$ and the ammonium removal capability was around $25 \%$. The higher adsorption capability against ammonium might be due to the interaction between positively charged ammonium and negatively charged sulfone groups. Nevertheless, this kind of removal was much lower than biological removal, therefore it was deduced that, MB and a

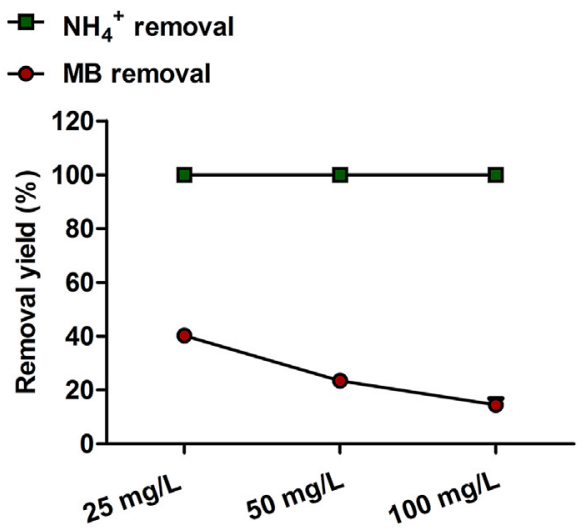

Initial pollutant concentration b

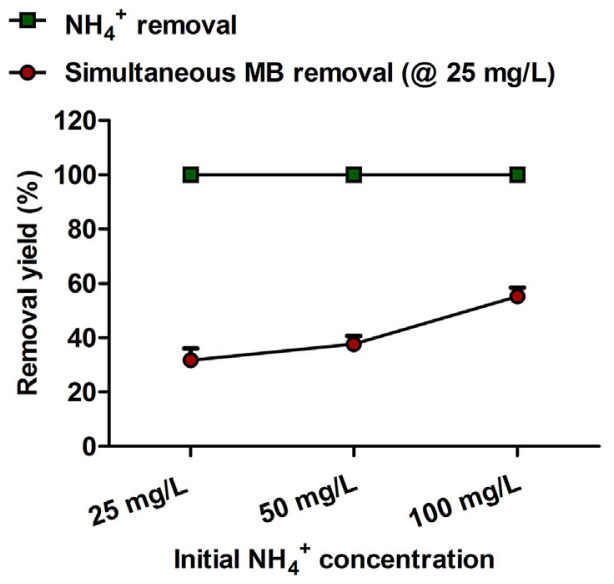

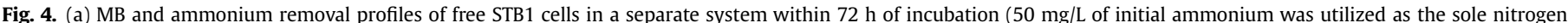

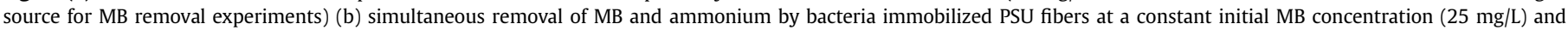
varying initial ammonium concentrations $(25,50,100 \mathrm{mg} / \mathrm{L})$ within $72 \mathrm{~h}$ of incubation.

was achieved for each concentration, while the removal efficiencies were lower for MB and the highest removal yield was achieved for ammonium removal capabilities of bacteria immobilized fibers were primarily due to the bacterial presence. 


\section{Conclusion}

In this study, morphology and fiber diameter differences of electrospun polysulfone (PSU) fibers on bacterial immobilization and bioremediation performances were evaluated. Aligned and randomly oriented electrospun PSU fibers were produced with thinner or thicker fiber diameters. These four different types of PSU fibers were utilized as carrier matrices for bacterial immobilization and then the sample showing highest bacterial immobilization was tested for bioremediation of ammonium and methylene blue dye in water. The results demonstrated that randomly oriented and thinner PSU fibers are favorable for bacterial immobilization among four different samples at equivalent conditions, hence further experiments were performed on this sample. Bacteria immobilized PSU fibers were found as promising for simultaneous removal of ammonium and methylene blue, though dye removal efficiency was lesser and optimization is required for higher dye removal performances. In addition, reusability of bacteria immobilized fibers was evaluated for ammonium removal at an initial concentration of $100 \mathrm{mg} / \mathrm{L}$ and found as potentially reusable. Overall, the results suggest that randomly oriented and thinner PSU fibers are favorable for bacterial integration and bacteria immobilized PSU fibers have a potential to be used in remediation of water systems.

\section{Acknowledgements}

The Scientific and Technological Research Council of Turkey (TUBITAK, project \#114Y264) is acknowledged for funding the research. Dr. Uyar acknowledges The Turkish Academy of Sciences Outstanding Young Scientists Award Program (TUBA-GEBIP) for partial funding of the research. A. Celebioglu acknowledges TUBITAK project \#113Y348 for a postdoctoral fellowship. O.F. Sarioglu acknowledges TUBITAK BIDEB $(2211-\mathrm{C})$ for National Ph.D. Scholarship.

\section{References}

Eroglu, E., Agarwal, V., Bradshaw, M., Chen, X., Smith, S.M., Raston, C.L., Iyera, K.S., 2012. Nitrate removal from liquid effluents using microalgae immobilized on chitosan nanofiber mats. Green Chem. 14, 2682-2685.
Greiner, A., Wendorff, J., 2007. Electrospinning: a fascinating method for the preparation of ultrathin fibers. Angew. Chem. Int. 46, 5670-5703.

Klein, S., Kuhn, J., Avrahami, R., Tarre, S., Beliavski, M., Green, M., Zussman, E., 2009. Encapsulation of bacterial cells in electrospun microtubes. Biomacromolecules $10,1751-1756$

Klein, S. Avrahami, R., Zussman, E., Beliavski, M., Tarre, S, Green, M., 2012. Encapsulation of Pseudomonas sp. ADP cells in electrospun microtubes for atrazine bioremediation. J. Ind. Microbiol. Biotechnol. 39, 1605-1613.

Malik, A., 2004. Metal bioremediation through growing cells. Environ. Int. 30, $261-278$.

NJDEP, 1997. Facts; Nitrate and Nitrite in DrinkingWater? Department of Health and Senior Services. New Jersey. online at. http://www.state.nj.us/health/eoh hhazweb/nitrate.pdf.

Ramakrishna, S., Fujihara, K., Teo, W., Lim, T., Ma, Z., 2005. An Introduction to Electrospinning and Nanofibers. World Scientific Publishing Company Singapore.

Salalha, W., Kuhn, J., Dror, Y., Zussman, E., 2006. Encapsulation of bacteria and viruses in electrospun nanofibres. Nanotechnology 17, 4675-4681.

San, N.O., Celebioglu, A., Tumtas, Y., Uyar, T., Tekinay, T., 2014. Reusable bacteria immobilized electrospun nanofibrous webs for decolorization of methylene blue dye in wastewater treatment. RSC Adv. 4, 32249-32255.

San-Keskin, N.O., Celebioglu, A., Uyar, T., Tekinay, T., 2015a. Microalgae immobilized nanofibrous web for removal of reactive dyes from wastewater. Ind. Eng. Chem. Res. 54, 5802-5809.

San-Keskin, N.O., Celebioglu, A., Sarioglu, O.F., Ozkan, A.D., Uyar, T., Tekinay, T., 2015b. Removal of a reactive dye and hexavalent chromium by a reusable bacteria attached electrospun nanofibrous web. RSC Adv, 5, 86867-86874.

Sarioglu, O.F., Suluyayla, R., Tekinay, T., 2012. Heterotrophic ammonium removal by a novel hatchery isolate Acinetobacter calcoaceticus STB1. Int. Biodeterior. Biodegrad. 71, 67-71.

Sarioglu, O.F., Yasa, O., Celebioglu, A., Uyar, T., Tekinay, T., 2013. Efficient ammonium removal from aquatic environments by Acinetobacter calcoaceticus STB1 immobilized on an electrospun cellulose acetate nanofibrous web. Green Chem. $15,2566-2572$

Sarioglu, O.F., Celebioglu, A., Tekinay, T., Uyar, T., 2015. Evaluation of Contact Time and Fiber Morphology on Bacterial Immobilization for Development of Novel Surfactant Degrading Nanofibrous Webs, vol. 5, pp. 102750-102758.

Sarioglu, O.F., Celebioglu, A., Tekinay, T., Uyar, T., 2016. Bacteria-immobilized electrospun fibrous polymeric webs for hexavalent chromium remediation in water Int. J. Environ. Sci. Tech. 13, 2057-2066.

Sarioglu, O.F., San-Keskin, N.O., Celebioglu, A., Tekinay, T., Uyar, T., 2017. Bacteria encapsulated electrospun nanofibrous webs for remediation of methylene blue dye in water. Colloids Surf. B 152, 245-251.

US EPA, 2009. Draft 2009 Update of Aquatic Life Ambient Water Quality Criteria for Ammonia - Freshwater. United States Environmental Protection Agency, Washington, DC.

Uyar, T., Besenbacher, F., 2008. Electrospinning of uniform polystyrene fibers: the effect of solvent conductivity. Polymer 49, 5336-5343.

Wendorff, J.H., Agarwal, S., Greiner, A., 2012. Electrospinning: Materials, Processing, and Applications. Wiley-VCH, Berlin. 